\section{(6) OPEN ACCESS}

PAPER

\title{
For love and money: the need to rethink benefits in HIV cure studies
}

\author{
Emily Largent
}

Correspondence to

Emily Largent, Program in

Health Policy, Harvard

University, Cambridge

MA 02138, USA;

elargent@fas.harvard.edu

Received 2 October 2015 Revised 28 January 2016 Accepted 18 February 2016 Published Online First 18 May 2016

\section{SLinked}

- http://dx.doi.org/10.1136/ medethics-2015-103111

CrossMark

To cite: Largent E. J Med Ethics 2017:43:96-99.

\section{ABSTRACT}

HIV cure research holds great potential to eradicate HIV, but the benefit to early trial participants is likely to be small. Moreover, participation carries unknown and possibly significant risks to research participants. This is the risk:benefit ratio challenge of HIV cure research. Although it may be consensual and rational for individuals to participate in HIV cure research that requires a degree of self-sacrifice, I argue that altruistic research participants can be exploited when the benefits to them are unfair. Transactions of this kind should not be prohibited, as that would be unacceptably paternalistic and thwart socially valuable research. Nevertheless, we should not simply accept these transactions but must work to reduce or eliminate exploitation by enhancing the benefits so that research participants are better off by their own lights. Offering payment in HIV cure research is the optimal way to enhance benefits to research participants and to make the risk:benefit ratio more favourable. I argue for a payment-as-benefit model against the standard view, assumed in ethics and policy, that offers of payment are not legitimate benefits.

\section{INTRODUCTION}

In 1988, Levine, a scholar working at the intersection of AIDS policy and ethics, observed: 'There is an enormous reservoir of altruism among the prospective [HIV] study population. The willingness to bear the burdens and inconveniences of the scientific research that will eventually bring about a way to manage this disease should not be wasted; neither should it be exploited'. ${ }^{1}$ Nearly three decades later, as researchers vigorously pursue a cure, my concern echoes Levine's second pointthat the altruism of participants in HIV cure studies should not be exploited.

HIV cure research aims at eliminating the need for continuous antiretroviral therapy. While the potential social benefit of 'eradicating HIV is great, the benefit to early trial volunteers is likely to be small. Importantly, studies that involve reactivating agents, treatment interruptions, bone marrow conditioning, stem cell transplantation or combination therapies carry unknown and possibly significant risks to volunteers'. ${ }^{2}$ My fear that participants' altruism will be exploited arises directly from the risk:benefit ratio challenge of HIV cure research, which is, at bottom, a concern that individual research participants are asked to assume too much risk in the course of these socially valuable studies.

This article draws on literature related to both altruism and offers of payment made to research participants and applies it to the specific context of HIV cure studies. I argue that in order to address the risk:benefit ratio challenge, which persists even when participants are altruistically motivated, it is necessary to look beyond the standard view of delineating research-related risks and benefits and to take payment seriously as a benefit.

\section{ALTRUISM IN HIV CURE RESEARCH}

Recent studies suggest that many potential participants in HIV cure studies are strongly motivated by altruism. ${ }^{3-5}$ Altruism is, of course, just one of many factors that may motivate individuals to participate in research. ${ }^{6}$ Yet, these other motivations may be significantly less potent in HIV cure research than in other contexts. For example, ' $[\mathrm{t}$ ] he investigational intervention is highly unlikely to have a direct benefit' for individual research participants. ${ }^{7}$ Additionally, the role of financial incentives is uncertain but likely small. Looking globally, it has been claimed that 'there are usually no financial incentives' for HIV cure trials. ${ }^{8}$ One study of consent documents for 13 HIV cure studies found a range from 'no payment to nearly $\$ 2,000$ ', though neither the median nor mean payment was identified. ${ }^{9}$ Given that, as of early 2016, there were well over 100 HIV cure-related clinical studies either being conducted or already completed worldwide, ${ }^{10}$ it remains unclear what the average offer of payment is.

Assuming no defect in informed consent (eg, a therapeutic misconception) and minimal financial incentives, an appeal to some degree of altruism is necessary to explain why participation in an HIV cure trial is fully rational. This reliance on altruistic motivation has a host of practical and ethical implications related, for instance, to recruitment and consent. Here, however, I will focus on its implications for the risk:benefit ratio challenge.

\section{Altruism as benefit}

The standard risk-benefit calculus does not account for research participants' motivations, including altruism. From a practical standpoint, this may be because it is often difficult to determine whether and to what extent altruistic impulses motivate a particular research participant. From a theoretical standpoint, this may be due to deep, persistent uncertainty about whether altruism benefits its possessor.

Individuals who are motivated to participate in HIV cure research for genuinely altruistic reasons could plausibly advance their personal well-being by contributing to research primarily (or even 
solely) intended to benefit future patients because they share the end for which the research is undertaken. Yet, in general, the research participant will be worse off because the gain from fused interests is outweighed by the significant risk of personal harm. From the participant's perspective, then, any altruistic benefit-which is not self-interested, though it does redound in part to the individual-serves to offset some but not all of the risks and burdens they are asked to assume.

On even the most favourable account, altruism involves a degree of self-sacrifice. Therefore, it is unnecessary to take a stand at present on the controversial question of whether altruism benefits its possessor. Whatever position one adopts, the inevitable conclusion is that, although altruism can justify some exposure to otherwise uncompensated risks, the risk:benefit ratio challenge persists.

\section{Altruism as limit}

The presence of altruistic motivation might lead us to worry less about the risk:benefit ratio challenge than we would in its absence. The argument goes that if research participants have genuinely altruistic motives, 'then it is easier to justify imposing costs and sacrifices on them in the course of a trial' than if they do not. ${ }^{11}$ This works, but only to a point.

There are limits to acceptable altruistic sacrifice. We can look to areas outside of clinical research to see that this is true, even when the value of the sacrifice is extraordinarily high to the person seeking to make it. For instance, in the medical context, a parent might be barred from donating a vital organ to a beloved child. ${ }^{12}$ Assuming that each person counts just as much as any other, someone who accepts excessive risks to benefit others-particularly a group as removed from one's self as 'future patients' - may not adequately value her own self-worth. Similarly, asking (or allowing) an individual to make excessive sacrifices for others does not show sufficient respect for the worth of the individual. The answer to the question of whether a particular altruistic sacrifice is acceptable will largely coincide with a determination that the risks to individual participants are reasonable in relation to the anticipated social benefits.

\section{Exploitation of altruism}

A determination that risks to participants are justified in light of the beneficial knowledge research might generate cannot ensure that participation in a particular HIV cure study will be consistent with the individual interests of any particular participant. According to Wertheimer's influential account, exploitation involves taking unfair advantage of another person. ${ }^{13}$ Exploitation occurs when, due to an asymmetry of bargaining power, one party to a transaction insufficiently benefits or assumes an unfair share of the burdens relative to other parties. In the research context, the research-related burdens and risks can become so high that, although altruistically motivated research participants willingly and rationally engage in an act of self-sacrifice, the lack of meaningful individual benefits renders participation unfair.

Thus, we can imagine HIV cure research characterised by the risk:benefit ratio challenge as arrayed along a spectrum. At one end, there are clearly permissible studies in which the degree of self-sacrifice is so low as to be acceptable. At the other end, research is impermissible because the burdens and risks to participants exceed the limits of acceptable self-sacrifice. And in the substantial middle, there are studies in which consensual exploitation is a concern because, although the degree of selfsacrifice is acceptable, there may nevertheless be unfairness in the transaction. Although drawing lines to demarcate these zones will be challenging, the ethical response at either extreme is clear. Going forward, therefore, I will focus on the middle zone.

\section{WHAT TO DO ABOUT EXPLOITATION?}

Macklin has asserted that there is 'clear agreement...on the proposition that [it] is unethical to exploit vulnerable populations or individual participants in the conduct of research'. ${ }^{14}$ Undoubtedly, this is true of non-consensual, harmful exploitation, the wrongness of which is self-evident. Yet, it is an open question whether we should, in general, prevent altruistically motivated individuals who give valid consent from being exploited.

The most compelling reason to intervene in such circumstances is to protect the research enterprise itself. ${ }^{15}$ Trust is crucial for the proper functioning of clinical research. ${ }^{16}$ Earning and preserving trust in clinical research requires, in part, adhering to standards of fair treatment. It is a profound miscalculation to see consensual exploitation as a relatively minor ethical violation for the sake of pursuing knowledge. Therefore, we should not simply accept these transactions but must work to reduce or eliminate exploitation in research when we find it.

There are at least two ways to eliminate consensual exploitation of altruistic research participants. The first of these is to prohibit HIV cure studies that are unfairly reliant on participants' willingness to sacrifice themselves for future patients. The second is to enhance the benefits that altruistic participants receive so as to make the risk:benefit ratio for the individual more favourable.

The first solution is untenable. There are those, like Jonas, who admonish us 'not [to] forget that progress is an optional goal'. ${ }^{17}$ While acknowledging that this is a blow to those whose diseases have not yet been vanquished, Jonas cautions that it is a greater harm to society to erode moral values whose loss 'would make its most dazzling triumphs not worth having'. ${ }^{17} \mathrm{I}$ do not wish to deny that some medical advances could be too dearly bought. Nevertheless, it would be an indefensible instance of hard paternalism to protect research participants from the potentially harmful consequences of their fully voluntary and rational undertakings, particularly when the research holds the potential to cure a disease about which they care deeply, and soft paternalism cannot justify denying prospective research participants an opportunity they might reasonably choose. ${ }^{18}$

This leaves the second solution: enhancing the level of benefits so as to render the individual risk:benefit ratio more favourable. Soft paternalism can justify interference that results in a transaction that is more beneficial to research participants by their own lights. ${ }^{15}$ I favour establishing an outer bound on the permissible disparity between risks and benefits to individual research participants. Admittedly, this could narrow the choice set prospective participants in HIV cure research may face, as some studies may not go forward under this constraint, but I rest unconvinced that respect for autonomy is an absolute principle. ${ }^{19}$

\section{Payment-as-benefit}

Discussions about exploitation in clinical research have typically focused on increasing the direct therapeutic benefit and/or increasing the collateral benefits to research participants in order to render the risk:benefit ratio more favourable. ${ }^{20}$ As discussed above, HIV cure trials typically do not offer direct therapeutic benefit. Therefore, any effort to address the risk:benefit ratio challenge in HIV cure trials must focus on increasing collateral benefits. 
One could imagine various ways of enhancing collateral benefits. Research participants might receive a mug, a certificate thanking them for their contribution, or public acknowledgement, for example, through publication of their names in the newspaper. They might be promised ancillary care or access to a cure when it is found. My preferred option is giving them money.

Payment to research participants, 'though technically a collateral benefit, is classified and treated separately in research ethics and policy'. ${ }^{21}$ The standard view, supported by the US federal regulations, is that 'extraneous benefits, such as payment... cannot be considered in delineating the benefits compared with the risks'. ${ }^{22}$ Only after an institutional review board (IRB) determines that risks are reasonable in relation to the overall benefits may it permit investigators to offer payment. Notably, '[a]lthough the standard view has become a virtual mantra in research ethics, no document contains an argument in its defense'. ${ }^{13}$ Much of the concern about offers of payment to research participants can be attributed to indefensible 'research exceptionalism'. 2324 i Society demonstrates a willingness to pay people to engage in a broad range of risky but socially beneficial activities, such as firefighting and construction. If research exceptionalism cannot be defended, consistency seemingly 'require[s] that[individuals] also be allowed to receive payments for participating in socially beneficial research involving serious risk'. ${ }^{25}$

HIV cure research places additional pressure on the standard view because it is difficult to see how the risk:benefit ratio challenge can be resolved if we are forced to rely solely on benefits the standard view recognises as legitimate. Let us face it: the last thing anyone needs is another mug, and having one's name published in a newspaper raises concerns about confidentiality, particularly the spectre of unwanted disclosure of HIV status. Moreover, these benefits are insignificant in the face of serious risks and uncertainty. More promising is the provision of ancillary care or access to any forthcoming cure. Yet, the provision of ancillary care may be complicated by the ethical requirement of scientific validity. As for access to a cure, it is unclear how long it will take to find one, and there is a real possibility that 'participation in an early HIV cure study could make individuals ineligible for later studies or future beneficial interventions'. That makes any promise of future access to a cure an elusive benefit at best.

Money, by contrast, is a benefit that you can take to the bank. The amount can be approved by IRBs, which routinely assess offers of payment. Offers of money do not raise confidentiality issues, though participants might have to disclose the income for tax purposes. Additionally, payment has the advantage of being infinitely scalable. Exactly what would count as an adequate offer of payment to address the risk:benefit ratio challenge is open to substantive debate and is not a question I seek to resolve here, though I suggest it should take into account other collateral benefits, if any, and will correlate with the risks inherent to the study (along the dimensions of both probability and magnitude) and associated uncertainty.

Because there are barriers to enhancing traditional collateral benefits, addressing the risk:benefit ratio challenge and associated concerns regarding exploitation of altruistic participants in HIV cure studies is best accomplished by departing from the

${ }^{\mathrm{i}}$ (Largent E, Lynch H. (forthcoming). Coercion, Undue Inducement, and Exploitation in Clinical Research: Regulatory Uncertainty, Conceptual Confusion, and a Path Forward) standard view-that is, by offering to pay research participants and acknowledging the payment for what it is, a benefit to the individual to offset risk. Even if one does not think that money itself can offset risks, one has to concede that it is instrumentally valuable and can buy many things that influence health and well-being, whether directly or indirectly.

\section{POSSIBLE OBJECTIONS}

I anticipate several objections.

\section{Minimising risk}

A common argument against accepting payment as a benefit is that this practice would reduce investigators' incentives to minimise risks to research participants. By simply adding more payment, the argument goes, investigators could render what would otherwise be an unfavourable risk:benefit ratio neutral or even advantageous. Yet, that is not a necessary feature of a payment-as-benefit model. First, research must have social value to be ethical; an offer of payment cannot make research lacking in social value acceptable. Second, there can be an independent requirement to decrease risk to the greatest feasible extent or to the somewhat less stringent greatest reasonable extent.

\section{Coercion and undue inducement}

A second objection is that offering payment as a benefit will invalidate informed consent, either by coercing or unduly influencing prospective research participants. Coercion, which negates the voluntariness of consent, necessarily entails a threat of harm. Genuine offers of payment cannot ever be coercive because they are not threats. ${ }^{26}$ An undue inducement, which negates the comprehension element of informed consent, is an excessive or improper offer that 'predictably triggers irrational decision-making given the agent's own settled (and reasonable) values and aims'. ${ }^{27}$ Many people perceive a tension between exploitation and undue influence. ${ }^{28}$ On the one hand, if you offer research participants too little, they are exploited. If, on the other hand, you offer them too much, their choice to participate may be unduly influenced. Yet, empirical data would lead us to question whether large payments actually distort the ability to evaluate risks. To the contrary, offers of payment may help people differentiate clinical research from clinical care and increase the time spent reviewing research-related risks. ${ }^{29} 30$ Concerns about exploitation should, therefore, be more salient than concerns about undue inducement. Even if we assume, however, that there is a plausible risk of undue inducement, reducing or eliminating the offer of payment is not the only way of addressing it. It is also possible to strengthen informed consent to ensure that enrolled participants do not suffer from a cognitive distortion.

\section{Incommensurability of risk and money}

Another objection is that the risks associated with human subject's research are incommensurate with money, and there is no way to quantify a 'fair' offer of payment. But this proves too much. IRBs routinely make apples-to-oranges comparisons between the social value of knowledge and risks to individual participants. To say they cannot weigh unlike things is to undermine the whole exercise of IRB review. Moreover, 'IRBs cannot refuse to make judgments about the value of financial benefits relative to risk...if they are concerned to ensure that financial payments do not constitute undue inducements' ${ }^{18}$ 


\section{Commodification}

Some commentators have expressed a belief that payment wrongfully commodifies research participation. If people should not be treated like commodities, the wrongness of that is not addressed by offering payment to make the risk:benefit ratio more favourable. To the contrary, it may 'brib[e] people to become commodities'. ${ }^{31}$ Research participation is appropriately analogised to unskilled, yet essential labour. ${ }^{32}$ In the context of unskilled labour people are generally permitted to sell their bodily services, even when that exposes them to risks. It should be 'no more worrisome to commodify a person's labor as a research subject than to commodify a person's labor in other contexts, which happens all the time'. ${ }^{25}$

\section{Extinguishing altruism}

A final objection-and the most compelling-is that social policy should not discourage recruitment of altruistically motivated individuals, and offering payment might have the perverse consequence of negatively affecting intrinsic motivation and reducing the pool of prospective research participants. ${ }^{33}$ Offers of payment might also selectively appeal to individuals who are somehow less desirable as research participants. ${ }^{34}$ While a number of experimental studies have examined the effects of extrinsic incentives on altruistic motivations in other contexts, such as blood donation, and generally found results consistent with the 'crowing out' hypothesis, ${ }^{35}$ the question of how offers of payment would affect recruitment in HIV cure research cannot be fully resolved here. Further empirical analysis is needed.

\section{CONCLUSION}

Many of the individuals who enrol in HIV cure studies appear to be strongly motivated by altruism. Great strides in clinical research are possible because these individuals are willing to selfsacrifice for the benefit of future patients. Is not it unnecessarily dirtying things up to introduce money? My answer is, 'No'.

Genuine altruistic motivation should allay our concerns about the risk:benefit ratio challenge up to a point. There is, however, a limit to the moral work altruism can do. Even when research participants share the ends of the research, there is a real danger that their altruistic impulses can be exploited by an unfair distribution of benefits and risks, and in extreme cases, risks may exceed the limits of acceptable self-sacrifice. Collateral benefits for those who participate in HIV cure research should be enhanced in order to minimise the possibility of exploitation and protect the integrity of the research enterprise. This is best accomplished by offering payment to participants. Ethicists working on HIV/AIDS have stated that 'ethical standards and oversight for HIV cure research must be as rigorous and cutting-edge as the science'. ${ }^{28}$ It is time to revisit the standard view and question whether offers of payment can-and should -be used as a legitimate benefit to offset research-related burdens and risks.

Funding National Institute of Allergy and Infectious Diseases (1 R01 Al114617-01A1) and (1 R56 Al114617-01).

Competing interests None declared.

Provenance and peer review Commissioned; externally peer reviewed.

Open Access This is an Open Access article distributed in accordance with the Creative Commons Attribution Non Commercial (CC BY-NC 4.0) license, which permits others to distribute, remix, adapt, build upon this work non-commercially, and license their derivative works on different terms, provided the original work is properly cited and the use is non-commercial. See: http://creativecommons.org/ licenses/by-nc/4.0/

\section{REFERENCES}

1 Levine C. Has AIDS changed the ethics of human subjects research? Law Med Health Care 1988;16:167-73.

2 Deeks SG, Autran B, Berkhout B, et al. Towards an HIV cure: a global scientific strategy. Nat Rev Immunol 2012;12:607-14.

3 Arnold MP, Evans D, Vergel N. Recruitment and ethical considerations in HIV cure trials requiring treatment interruption. Virus Eradication 2015;1:43-8.

4 Kall M, Simmons R, Collins $S$, et al. Altruism and medical advice are key factors in decision-making about participating in HIV cure research: results from a UK-wide survey of people living with HIV. BHIVA Conference, Brighton, April 2015, abstract P159.

5 Simmons R, Porter K, Kall M, et al. A UK survey of HIV-positive people's attitudes towards cure research. BHIVA conference, Brighton, April 2015, abstract P39. FDA (2014), The Voice of the Patient: Human Immunodeficiency Virus (HIV) Patient-Focused Drug Development and HIV Cure Research, http://www.fda.gov/ downloads/ForIndustry/UserFees/PrescriptionDrugUserFee/UCM393273.pdf

6 Stunkel L, Grady C. More than the money: a review of the literature examining healthy volunteer motivations. Contemp Clin Trials 2011;32:342-52.

7 Lo B, Grady C, Working Group on Ethics of the International AIDS Society. Ethical considerations in HIV cure research: points to consider. Curr Opin HIV AIDS 2013:8:243-9.

8 Power J. Risks vs rewards: why people with HIV volunteer for 'cure' research, The Conversation, http://theconversation.com/risks-vs-rewards-why-people-with-hivvolunteer-for-cure-research-41182 (last visited 20 January 2016).

9 Henderson GE. The ethics of HIV "cure" research: what can we learn from consent forms? AIDS Res Hum Retroviruses 2015;31:56-63.

10 Treatment Action Group. Research Toward a Cure Trials, http://www. treatmentactiongroup.org/cure/trials (last visited 20 January 2016).

11 Jansen LA. The ethics of altruism in clinical research. Hastings Cent Rep 2009:39:26-36.

12 Sauder R, Parker LS. Autonomy's limits: living donation and health-related harm. Camb Q Healthc Ethics 2001;10:399-407.

13 Wertheimer A. Exploitation. Princeton University Press, 1999.

14 Macklin R. After Helsinki: unresolved issues in international research. Kennedy Inst Ethics J 2001;11:17-36.

15 Miller FG, Wertheimer A. Facing up to paternalism in research ethics. Hastings Cent Rep 2007;37:24-34.

16 Largent EA. What's trust got to do with it? Trust and the importance of the research-care distinction. Am J Bioeth 2015;15:22-4.

17 Jonas H. Philosophical reflections on experimenting with human subjects. Daedalus 1969;219-47.

18 Wertheimer A. Is payment a benefit? Bioethics 2013;27:105-16.

19 Gillon R. Autonomy and the principle of respect for autonomy. Br Med J (Clin Res Ed) 1985;290:1806-8

20 Ballantyne $A$. Benefits to research subjects in international trials: do they reduce exploitation or increase undue inducement? Dev World Bioeth 2008;8:178-91.

21 King NM. Defining and describing benefit appropriately in clinical trials. J Law Med Ethics 2000;28:332.

22 Emanuel EJ, Wendler D, Grady C. What makes clinical research ethical? JAMA 2000;283:2701-11.

23 Largent E, Grady C, Miller FG, et al. Misconceptions about coercion and undue influence: reflections on the views of IRB members. Bioethics 2013;27:500-7.

24 Wilson J, Hunter D. Research exceptionalism. Am J Bioeth 2010;10:45-54.

25 Ackerman TF. An ethical framework for the practice of paying research subjects. IRB 1989;11:1-4. Ethics and Human Research

26 Wertheimer A, Miller FG. Payment for research participation: a coercive offer? J Med Ethics 2008;34:389-92.

27 Macklin R. The paradoxical case of payment as benefit to research subjects. IRB 1989:11:1-3.

28 Cryder CE, John London A, Volpp KG, et al. Informative inducement: study payment as a signal of risk. Soc Sci Med 2010;70:455-64.

29 Halpern SD, Karlawish JH, Casarett D, et al. Empirical assessment of whether moderate payments are undue or unjust inducements for participation in clinical trials. Arch Intern Med 2004;164:801-3.

30 Dickenson D. Consent, commodification and benefit-sharing in genetic research. Dev World Bioeth 2004;4:109-24.

31 Dickert N, Grady C. What's the price of a research subject? Approaches to payment for research participation. N Engl J Med 1999;341:198.

32 Lynch HF. Human research subjects as human research workers. Yale J Health Policy Law Ethics 2014;14:122.

33 Titmuss RM. The gift relationship: from human blood to social policy. New York: New Press, 1997.

34 Glynn SA, Williams AE, Nass CC, et al. Attitudes toward blood donation incentives in the United States: implications for donor recruitment. Transfusion 2003:43:7-16.

35 Lacetera N, Macis M. Do all material incentives for pro-social activities backfire? The response to cash and non-cash incentives for blood donations. J Econ Psychol 2010;31:738-48. 